\title{
CUSTOS DE PRODUÇÃO DA SOJA CULTIVADA SOB SISTEMA DE PLANTIO DIRETO: ESTUDO DE MULTICASOS NO OESTE DA BAHIA ${ }^{1}$
}

\author{
Production costs for soybean under systems of direct planting: multicase \\ study in the west region of the state of Bahia, Brazil
}

\author{
Sílvio Henrique de Castro ${ }^{2}$, Ricardo Pereira Reis ${ }^{3}$, André Luís Ribeiro Lima $^{4}$
}

\begin{abstract}
RESUMO
Por meio deste estudo, buscou-se estimar os custos de produção da soja grão, cultivada sob sistema de plantio direto, na região Oeste do Estado da Bahia. Para tanto, coletaram-se dados técnicos e econômicos para a elaboração de custos referentes ao empreendimento de quatro fazendas dessa região, obtidos junto aos técnicos responsáveis pela sojicultura em estudo, caracterizando-se como estudo de multicasos. A pesquisa baseia-se na teoria de custos e o período de análise correspondeu à safra de verão 2003/2004. As despesas com os custos variáveis foram as que mais oneraram os custos finais da atividade, destacando-se gastos com fertilizantes, serviços e defensivos químicos. Entre os itens que compõem os custos fixos, destacaram-se gastos com máquinas e equipamentos e o custo de oportunidade da terra. Economicamente, concluiu-se que a atividade produtiva em estudo se encontra em processo de descapitalização, visto que parte do capital fixo aplicado na produção não foi totalmente pago. Tal constatação leva a perda da capacidade produtiva e no longo prazo o sojicultor pode ser levado a aplicar seu capital em outra atividade produtiva ou em outra alternativa de investimento.
\end{abstract}

Termos para indexação: Custos de produção, soja, plantio direto, Oeste da Bahia.

\begin{abstract}
The production costs for soybean in the west region of the state of Bahia are presented in this study. This research identifies economic indexes of cost that most influence decisions made by soybean producers. The research is based on theory of costs. The data on the four soybeans productions units were gathered in the harvest from 2003 to 2004, characterizing a multicase study. The economic analysis proved that soybeans prices were below average total cost but exceeded average variable cost. Thus, not all of the fixed costs are lost, as would be the case if production were discontinued. The research shows that expenses on variable resources represent the greater portion of the final cost of soybean, like cost with fertilizers, services and quimical products. The itens with fixed cost which affected most of cost of soybean productions in the west of Bahia were machinery, equipment and cost of land.The economic study indicated that not all of de fixed costs are lost, as would be the case if production were discontinued. However, the soybean entrepreneur could be produce only in short run, but in the process of descapitalization. In this case, in the long run these producers could earn in the best economically alternative use of theirs investments.
\end{abstract}

Index terms: Production costs, soybean, direct plantation, west of Bahia.

(Recebido para publicação em 19 de julho de 2005 e aprovado em 6 abril de 2006)

\section{INTRODUÇÃO}

O sistema agroindustrial da soja é um dos mais importantes no cenário do agronegócio mundial. A soja, consumida in natura ou como matéria-prima básica na produção do farelo e do óleo, dentre outros produtos, é uma das principais commodities, sendo cultivada comercialmente no Brasil há pouco mais de 40 anos. Os agricultores que se dedicam ao seu cultivo empregam altas tecnologias em todas as fases de produção, as quais incrementam produtividade e qualidade ao produto colhido.

No entanto, a sojicultura não deixa de ser uma atividade empresarial de alto risco, visto que existem fatores que independem da dedicação e aporte tecnológico do empresário, tais como o clima e o preço do produto.
A grande maioria das lavouras de soja para produção de grão é cultivada em áreas extensas e em regime de sequeiro, sendo as chuvas o principal fator climático que pode limitar a produção, conforme sua frequiência e quantidade. As fases de germinação e floração/enchimento das vagens são as que mais requerem chuvas para que a lavoura produza satisfatoriamente. Já no período da colheita, as chuvas passam a ser indesejáveis. Com vistas a minimizar riscos climáticos, há no mercado seguros agrícolas que podem ser contratados pelo agricultor, dependendo do município, mas muitos ainda preferem apostar na ocorrência de condições climáticas favoráveis, até porque os seguros oneram ainda mais o custo de produção, com taxas oscilando de 4 a $6 \%$, conforme a região e a seguradora.

\footnotetext{
${ }^{1}$ Parte da monografia apresentada no Curso de Pós-Graduação Lato Sensu, Ensino a Distância em Gestão Agroindustrial - Universidade Federal de Lavras/UFLA.

Especialista em Gestão Agroindustrial - silvioh3@ig.com.br

${ }^{3}$ Professor Titular do Departamento de Administração e Economia - Universidade Federal de Lavras/UFLA - Cx. P. 3037 - $37.200-000$ - Lavras, MG ricpreis@ufla.br

${ }^{4}$ Mestrando em Administração - Universidade Federal de Lavras/UFLA - Cx. P. 3037 - 37.200-000 - Lavras, MG - andreluisnep@yahoo.com.br
} 
O preço da saca de soja, definido em grandes centros de comercialização, tais como a Bolsa de Chicago nos EUA, é hoje um dos pontos limitantes à rentabilidade obtida pelo empresário produtor dessa oleaginosa. Mesmo havendo instrumentos consolidados de seguro de preços e comercialização futura, e por mais assertivo que tentem ser os analistas de mercado em suas previsões, sempre haverá incerteza quanto ao valor desta commodity para as safras futuras. Contribuem para esta incerteza o fato da China ser hoje um dos principais compradores deste produto e os Estados Unidos serem o maior produtor mundial do mesmo, sendo responsável por aproximadamente metade de toda a soja produzida internacionalmente. Tais fatores limitam a influência do princípio da livre concorrência, devido a uma considerável centralização da oferta e demanda.

No entanto, dos indicadores que estimam a rentabilidade de uma atividade econômica, o custo de produção é aquele que possibilita controle por parte do empresário produtor, o qual, após uma análise dos itens que o compõem, pode buscar alternativas com vistas a reduzi-lo, tais como a substituição de insumos onerosos por outros similares mais baratos e de semelhante eficiência, a mecanização de operações manuais ou viceversa, dependendo da dimensão do empreendimento e do nível tecnológico adotado, dentre outras medidas eventualmente sugestivas, conforme a situação em questão.

No Estado da Bahia, a soja vem sendo cultivada há pouco mais de dez anos, principalmente no extremo oeste, alcançando, nos últimos anos, excelentes produtividades. Na safra 2003/2004, o profissionalismo dos produtores baianos os levou a aplicação de técnicas no controle da ferrugem asiática, doença que afetou a atividade a partir de 2001, e foi considerado um exemplo a ser seguido em todo o País.

Dos três estados que cultivam a soja na região Nordeste (BA, MA e PI), a Bahia é aquele que possui maior área cultivada e maior produtividade. Segundo dados do Anuário Brasileiro da Soja, citados por Santos el al. (2004), na safra 2003/2004 foram cultivados 21.243 .700 hectares de soja no Brasil, com uma produção total de 49.781 .600 toneladas. Deste total, a Bahia participou com uma área de cultivo de 821.500 hectares e uma produção total de 2.218.100 toneladas, obtendo uma produtividade média de $2.700 \mathrm{~kg} / \mathrm{ha}$, sendo uma das maiores do País.

Nesse sentido, destaca-se a importância em estimar o custo de produção da soja nessa promissora região do País, com vistas a identificar os fatores produtivos que mais têm influenciado na definição do seu valor, bem como para se traçar um panorama futuro a curto e médio prazo, no que diz respeito à manutenção, expansão ou retração desta atividade, com reflexo direto na geração de emprego e riqueza para o Estado da Bahia. É um indicativo ao sojicultor baiano de como melhor a gestão dos custos de produção, na busca da eficiência produtiva, bem como traçar expectativas mais realistas quanto à sua permanência na atividade.

Por meio deste estudo, busca-se estimar os custos de produção da soja cultivada sob sistema de plantio direto na região Oeste da Bahia, identificando e avaliando os indicadores técnicos e econômicos de custos que mais afetam a decisão do empresário sojicultor no seu processo produtivo.

\section{MATERIAL E MÉTODO}

\section{Considerações teóricas}

A relação entre custo total e produção tem por base os fundamentos teóricos ligados à tecnologia, aos preços de insumos e à busca da eficiência na alocação dos recursos produtivos. O custo total de produção constitui-se na soma de todos os pagamentos efetuados pelo uso dos recursos e serviços, incluindo o custo alternativo do emprego dos fatores produtivos (REIS et al., 2001a).

$\mathrm{Na}$ teoria do custo, para efeito de planejamento, deve-se determinar o período de tempo, que pode ser curto ou longo. No curto prazo, os recursos utilizados são classificados em custos fixos e variáveis, sendo fixos aqueles que não se incorporam totalmente ao produto, mas o fazem em tantos ciclos produtivos quanto permitir sua vida útil. Os custos variáveis, por sua vez, têm duração igual ou inferior ao curto prazo e incorporam-se ao produto, necessitando ser reposto a cada ciclo do processo produtivo.

Dos custos totais, que constituem a soma dos fixos e variáveis, se obtêm os custos médios ou unitários, que representam o custo de uma unidade do produto. Esses custos fixos e variáveis são ainda decompostos em custos operacionais e alternativos (ou de oportunidade). Os operacionais constituem os valores correspondentes às depreciações e aos gastos com insumos, mão-de-obra, manutenção e despesas gerais. Somando-se o custo operacional ao custo alternativo, obtém-se o custo econômico.

Os resultados das condições de mercado e rendimento da empresa agropecuária (ou atividade produtiva) são medidos pelo preço do produto ou pela 
receita média. A receita média pode ser considerada o preço do produto mais o valor médio das vendas de produtos secundários (subprodutos).

Comparando-se a receita média ou o preço com os custos totais médios, obtém-se a análise econômica da atividade por unidade produtiva, identificando a lucratividade do empreendimento. No caso da análise operacional, ao comparar-se a receita média ou o preço com os custos operacionais, tem-se o conceito de resíduo ou margem (líquida ou bruta) de cada unidade produzida (REIS, 2002).

Para esse autor, só haverá lucro econômico na atividade produtiva se o preço do produto ou receita média for maior que o custo unitário de produção. Neste caso, o bem produzido proporciona um retorno que supera os custos alternativos, que é a remuneração ao capital e ao trabalho empregados na atividade. É uma situação econômica que estimula a entrada de novas empresas, atraindo investimentos competitivos.

Se o preço do produto ou receita média for igual ao custo médio de produção, trata-se do chamado lucro normal, o que significa estabilidade, mantendo assim o nível de produção a curto e longo prazo.

Se o preço do produto for suficiente apenas para cobrir parte dos custos fixos (e todo o custo variável), a atividade encontra-se em processo de descapitalização e em condições de produzir apenas no curto prazo. Neste caso, pode-se utilizar o custo operacional para análise de rentabilidade do empreendimento, desconsiderando o custo do capital aplicado na atividade, ou seja, o custo de oportunidade.

A base metodológica dos fundamentos dos custos de produção aplicados neste estudo pode ser encontrada nos textos e artigos apresentados por Lopes (2006), Reis $(1992,2002)$ e Reis et al. (2001a,b). Autores como Botrel (2002), Richetti \& Melho Filho (2002), Richetti \& Reis (2003) e Tourino (2000), conceituaram e aplicaram a teoria de custos nas análises técnica e econômica da cultura da soja nas regiões do Sul de Minas Gerais, Mato Grosso do Sul e Mato Grosso.

\section{Considerações analíticas}

A avaliação dos custos da sojicultura está fundamentada na operacionalização dos recursos econômicos que compõem os custos fixos e variáveis.

$\mathrm{Na}$ estimativa dos custos fixos utilizou-se a depreciação apropriada pelo método linear. Os recursos analisados no processo produtivo dessa atividade foram: terra, benfeitorias, máquinas, equipamentos e impostos fixos. No caso da terra, o seu custo é apropriado por meio do valor de arrendamento (aluguel), ou seja, o rendimento alternativo deste fator de produção. Para os demais recursos fixos, além do custo alternativo, estimou-se a depreciação de cada item.

Quanto aos custos variáveis, consideraram-se as despesas com sementes, adubação de plantio e cobertura (fertilizantes como fontes de fósforo, cloreto de potássio, micronutrientes, etc), inoculantes, defensivos químicos (inseticidas, fungicidas, herbicidas, etc), mão-de-obra (permanente e temporária), serviços de terceiros, manutenção, combustível, energia elétrica, impostos variáveis e demais despesas gerais.

Para efeito de análise do custo alternativo dos recursos produtivos alocados na sojicultura, considerouse a taxa de juros real de $12 \%$ a.a., exceção feita ao item terra, cujo custo alternativo foi o valor de arrendamento na região estudada.

No Anexo deste trabalho constam-se às terminologias e procedimentos de estimativa de custos, além da proposta das planilhas de custos fixos e variáveis de produção utilizadas no estudo.

Na sojicultura em estudo, ocorre apenas a produção da soja grão, o que caracteriza tal atividade como uma exploração típica de apenas um produto. A exceção fica por conta das lavouras de soja com a finalidade e aporte tecnológico apropriados para produção de soja semente, em que normalmente ocorre a produção simultânea de semente, nos campos classificados/aprovados, sendo que a produção obtida nos campos desclassificados pelo Ministério da Agricultura é comercializada como soja grão.

\section{Área de estudo e fonte de dados}

A região de estudo foi o Oeste do Estado da Bahia, onde, devido ao relevo privilegiado e a boa quantidade e frequiência das chuvas de verão, há em torno de um milhão de hectares explorados com agricultura há mais de uma década, sendo que destes, mais de 800.000 hectares estão ocupados com lavouras de soja. Foram colhidas planilhas de custos referentes à sojicultura empreendida em quatro propriedades desta região, no período de julho de 2003 a junho de 2004 (safra 2003/2004).

A sojicultura é uma atividade agrícola que requer elevada tecnologia em todas as fases de sua produção. Por isso, os agricultores que optam pela cultura da soja apresentam aporte tecnológico semelhante, com diferenças pouco expressivas.

O levantamento das informações consistiu na solicitação formal dos custos inerentes a todas as fases do 
processo produtivo, cultivado sob sistema de plantio direto, junto aos agrônomos responsáveis pela condução dos empreendimentos.

Considerando as características do estudo, os sojicultores foram selecionados de forma intencional, optando-se por produtores com maior senso de organização e controle, para que as informações prestadas fossem mais abrangentes e detalhadas. Cada produtor foi um caso e a pesquisa foi caracterizada como um "estudo de multicasos" na região Oeste da Bahia.

$\mathrm{O}$ estudo de casos consiste no exame de um conjunto de ações em em desenvolvimento e mostra como os princípios teóricos se manifestam nessas ações. Razões de ordem metodológicas, as quais tornam os estudos de caso uma forma legítima de pesquisa, assentam-se em considerações que podem ilustrar generalizações em diferentes contexto, constituindo-se num teste de uma teoria e podem estimular a formulação de hipóteses que orientarão novas pesquisas (MURRAY, 1974, citado por ALENCAR, 2000).

\section{RESULTADOS E DISCUSSÃO}

Os resultados desta pesquisa estão apresentados e discutidos nesta seção, considerando a participação dos itens dos custos fixos e variáveis no custo final da produção da soja grão, os valores dos custos de produção, a receita e a análise econômica da sojicultura na região Oeste da Bahia.

Entre as quatro propriedades pesquisadas, a área média destinada à sojicultura foi de 1.570 hectares, com uma produtividade de $3.235,91 \mathrm{~kg} / \mathrm{ha}$, ou 53,93 sacas de 60 $\mathrm{kg} / \mathrm{ha}$, na safra de verão 2003/2004.

Na Tabela 1, são apresentados os percentuais de participação dos itens que compõem os custos totais de produção da sojicultura no Oeste da Bahia.

Conforme os dados dessa Tabela, percebe-se que os custos fixos representaram $30,47 \%$ do custo final de produção da sojicultura, e os custos variáveis, 69,53\%. A maior participação dos custos fixos ficou com as despesas referentes à depreciação e custo de oportunidade do capital empregado em máquinas e equipamentos $(12,49 \%)$, seguido pelo custo de arrendamento do fator terra $(10,14 \%)$.

TABELA 1 - Composição percentual média dos custos fixos e variáveis da produção de soja grão, cultivada sob sistema de plantio direto, região Oeste da Bahia, período de julho/2003 a junho/2004.

\begin{tabular}{|c|c|}
\hline Itens de custo & Custo Total (CT) \% \\
\hline Máquinas e equipamentos & 12,49 \\
\hline Benfeitorias & 7,69 \\
\hline Terra & 10,14 \\
\hline Imposto Territorial Rural & 0,15 \\
\hline Custo Fixo Total (CFT) & 30,47 \\
\hline Sementes & 3,05 \\
\hline Fertilizantes $^{1}$ & 23,12 \\
\hline Corretivos de acidez & 0,60 \\
\hline Despesas gerais $^{2}$ & 7,72 \\
\hline Defensivos químicos ${ }^{3}$ & 11,60 \\
\hline Serviços de operações mecânicas ${ }^{4}$ & 15,98 \\
\hline Custo Variável Total (CVT) & 62,07 \\
\hline Custo alternativo & 7,46 \\
\hline Custo Total de Produção (CT) & 100,00 \\
\hline
\end{tabular}

${ }^{1}$ Inoculante, adubação de plantio, adubação de cobertura, micro-nutrientes.

${ }^{2}$ Manutenção de máquinas, equipamentos e benfeitorias, Funrural, transporte interno.

${ }^{3}$ Inseticidas, fungicidas, herbicidas, adjuvantes.

${ }^{4}$ Mão-de-obra, combustíveis e energia elétrica utilizada no preparo solo, plantio, tratos culturais, colheita, recepção, pré-limpeza e armazenagem. 
Quanto aos custos variáveis, os gastos com fertilizantes representaram $23,12 \%$ e as despesas com serviços (combustíveis e mão-de-obra), desde a fase de preparação do solo até a pós-colheita (recepção, limpeza e armazenagem), atingiram 15,98\% do custo final de produção da sojicultura.

Avaliando-se a participação dos itens que mais contribuíram no valor total dos custos fixos de produção, observa-se que os custos de colheitadeiras $(4,43 \%)$, tratores $(3,00 \%)$ e pulverizadores motorizados $(2,74 \%)$ foram os de maior participação no custo de máquinas e equipamentos. Já no custo de benfeitorias, que representou $7,69 \%$ da despesa final de produção de soja, as maiores participações foram com os silos metálicos graneleiros $(3,91 \%)$ e armazém graneleiro convencional e galpão para abrigo de máquinas e equipamentos $(1,37 \%)$.

Pela Tabela 1, também é possível discriminar os componentes que mais contribuíram no valor dos custos variáveis de produção. Entre as despesas com fertilizantes, que participaram com $23,12 \%$ do custo da sojicultura analisada, o principal componente foi a adubação de plantio, que representou $22,48 \%$.

As despesas com serviços de operações mecânicas representaram $15,98 \%$ do custo final da presente exploração analisada, destacando-se os tratos culturais $(5,68 \%)$ e a colheita $(5,32 \%)$.

Quanto aos defensivos químicos empregados na atividade, responsáveis por $11,60 \%$ do custo final de produção, os herbicidas representaram $5,42 \%$; fungicidas, $3,84 \%$; inseticidas, $2,12 \%$ e adjuvantes, $0,22 \%$.

No tocante às despesas gerais, com $7,72 \%$ do custo final de produção, o item que mais contribuiu para este percentual foram as despesas com manutenção de máquinas e equipamentos, com $2,87 \%$, seguidas pela despesa com Funrural $(2,24 \%)$, manutenção de benfeitorias $(1,69 \%)$ e transporte interno $(0,91 \%)$.
$\mathrm{Na}$ composição dos custos de produção supracitados, considerou-se que a terra utilizada para cultivo já estivesse com a acidez, níveis de fósforo e potássio devidamente corrigidos, sendo que os corretivos e fertilizantes considerados foram os destinados à manutenção da lavoura, absorvidos pela mesma ao longo do seu ciclo.

$\mathrm{Na}$ Tabela 2, constam os resultados dos custos médios da produção de soja grão, cultivada sob sistema de plantio direto, na região Oeste da Bahia, no período de julho de 2003 a junho de 2004.

Nesse período, a receita média da atividade de produção estudada foi de $\mathrm{R} \$ 35,00$ por saca de $60 \mathrm{~kg}$ de soja grão.

Os custos operacionais fixos e variáveis foram cobertos pela receita média (RMe) da atividade, ou seja, o custo operacional total médio (CopTMe) de $\mathrm{R} \$ 26,57$ por saca de $60 \mathrm{~kg}$ de soja grão foi inferior à receita recebida pelo sojicultor (Tabela 2). Essa situação indica que a atividade agrícola estudada teve um resíduo positivo (RMe > CopTMe). Contudo, essa remuneração obtida é menor que o custo total médio (CTMe) da atividade quando se consideram os custos de oportunidade do capital aplicado na sojicultura em estudo.

Analisando-se os custos econômicos, a situação é de descapitalização (CTMe > RMe > CVMe). Isto indica que a sojicultura tem condições de continuar a produzir no curto e médio prazo, pois cobre todos os seus custos variáveis e parte dos fixos. No entanto, parte do custo de oportunidade do capital aplicado na atividade não está sendo reposta (CTMe > RMe > CopTMe).

Dos custos econômicos analisados na Tabela 2, podem-se decompor os custos operacionais e os de oportunidade. Percebe-se que os custos operacionais, representados pelas depreciações do capital fixo e pelos fatores variáveis (semente, fertilizantes, corretivos de acidez,

TABELA 2 - Custos econômicos, operacionais e receita média da produção de soja grão, cultivada sob sistema de plantio direto, região Oeste da Bahia, período de julho/2003 a junho/2004.

\begin{tabular}{cccc}
\hline $\begin{array}{c}\text { Custo Fixo Médio } \\
\text { (CFMe) } \\
(\mathrm{R} \$ / \mathrm{sc})\end{array}$ & $\begin{array}{c}\text { Custo Variável Médio } \\
(\mathrm{CVMe}) \\
(\mathrm{R} \$ / \mathrm{sc})\end{array}$ & $\begin{array}{c}\text { Custo Total Médio } \\
(\mathrm{CTMe})^{1} \\
(\mathrm{R} \$ / \mathrm{sc})\end{array}$ & $\begin{array}{c}\text { Receita Média } \\
(\mathrm{RMe}) \\
(\mathrm{R} \$ / \mathrm{sc})\end{array}$ \\
\hline 11,69 & 26,67 & 38,36 & 35,00 \\
\hline $\begin{array}{c}\text { Custo Operacional } \\
\text { Fixo Médio (CopFMe) } \\
(\mathrm{R} \$ / \mathrm{sc})\end{array}$ & $\begin{array}{c}\text { Custo Operacional Variável } \\
\text { Médio (CopVMe) } \\
(\mathrm{R} \$ / \mathrm{sc})\end{array}$ & $\begin{array}{c}\text { Custo Operacional Total } \\
\text { Médio (CopTMe) }\end{array}$ & $\begin{array}{c}\text { Receita Média } \\
(\mathrm{RMe}) \\
(\mathrm{R} \$ / \mathrm{sc})\end{array}$ \\
\hline 2,76 & 23,81 & $\mathrm{R} \$ \mathrm{sc})$ & 35,00 \\
\hline
\end{tabular}

${ }^{1} \mathrm{O}$ custo total médio pode ser decomposto em custo operacional médio e custo de oportunidade.

Ciênc. agrotec., Lavras, v. 30, n. 6, p. 1146-1153, nov./dez., 2006 
despesas gerais, defensivos químicos e serviços de operações), representam $69,26 \%$ do custo econômico de cada saca de $60 \mathrm{~kg}$ de soja grão produzido na atividade agrícola da região Oeste da Bahia, período de julho de 2003 a junho de 2004. Nesse caso, o custo alternativo do capital investido na sojicultura representou $30,74 \%$ de cada saca de $60 \mathrm{~kg}$ de soja grão produzido na região estudada, resultado da diferença entre o custo econômico e o custo operacional.

\section{CONCLUSÕES}

Considerando-se os indicadores econômicos estimados nesta pesquisa, pode-se concluir que os custos variáveis são os que mais oneraram o custo final da sojicultura na região Oeste da Bahia. Os itens de maior participação no custo de produção de soja grão foram o custo de máquinas e equipamentos, no caso dos custos fixos e os gastos com fertilizantes, serviços de operações de máquinas e defensivos químicos, entre os custos variáveis.

Economicamente, a atividade agrícola estudada está em um processo de descapitalização, visto que parte do capital fixo aplicado na exploração não foi totalmente paga. A tendência é continuar a produção no curto e médio prazo levando a perda da capacidade produtiva. Mas, se persistir tal situação, em que parte do custo de oportunidade do capital aplicado na atividade não está sendo totalmente coberta pela receita média recebida, no longo prazo é possível que os produtores de soja grão busquem novas alternativas de exploração agropecuária e/ou aplicação do capital.

$\mathrm{O}$ resultado da análise operacional confirma esse processo de descapitalização, em que a receita média da atividade agrícola é superior ao custo operacional total médio mas inferior ao custo total médio de produção. Conclui-se que a exploração está cobrindo todos os custos operacionais, mas rendendo menos que o valor alternativo do capital aplicado.

Considerando que os produtores de soja grão estão em um segmento competitivo, ao contrário da agroindústria compradora que tem capacidade de formar preços, os produtores de soja necessitam administrar os fatores produtivos que estão sob seu controle, que é a estratégia de reduzir os seus custos de produção. Neste sentido, podem-se mencionar como alternativas gerenciais aplicáveis o plantio de cultivares que conciliem a uma maior produtividade e resistência a pragas e doenças, o uso de insumos de menor custo e semelhante eficácia, a busca constante pela otimização da relação custo/benefício ao optar pela locação ou aquisição de máquinas e implementos, bem como seu adequado dimensionamento, dentre outras.

\section{REFERÊNCIAS BIBLIOGRÁFICAS}

ALENCAR, E. Métodos de pesquisa nas organizações. Lavras: UFLA/FAEPE, 2000. 109 p.

BOTREL, E. P. Rendimento forrageiro da alfafa em relação a soja sucedido por milheto ou milho. 2002. 82 p. Tese (Doutorado em Agronomia) - Universidade Federal de Lavras, Lavras, 2002.

LOPES, P. F. Custos e escala de produção na pecuária leiteira: um estudo nos principais estados produtores do Brasil. 2006. 86 p. Dissertação (Mestrado em Administração) - Universidade Federal de Lavras, Lavras, 2006.

REIS, R. P. Estrutura produtiva da pecuária leiteira sob condições de intervenção: um estudo de caso em Minas Gerais. 1992. 151 f. Tese (Doutorado em Economia Rural) - Universidade Federal de Viçosa, Viçosa, 1992.

REIS, R. P. Fundamentos de economia aplicada. Lavras: UFLA/FAEPE, $2002.95 \mathrm{p}$.

REIS, R. P.; MEDEIROS, A. L.; MONTEIRO, L. A. Custos de produção da atividade leiteira na região sul de Minas Gerais. Organizações Rurais \& Agroindustriais, Lavras, v. 3, n. 2, p. 45-54, jul./dez. 2001a.

REIS, R. P.; REIS, A. J. dos; FONTES, R. E.; TAKAKI, H. R. C.; CASTRO JÚNIOR, L. G. de. Custos de produção da cafeicultura no sul de Minas Gerais. Organizações Rurais \& Agroindustriais, Lavras, v. 3, n. 1, p. 37-44, jan./jun. 2001 b.

RICHETTI, A.; MELO FILHO, G. A. de. Estimativa do custo de produção de soja, safra 2002/03, para Mato Grosso do Sul e Mato Grosso. Dourados: Embrapa, 2002. 6 p. (Comunicado técnico, 58).

RICHETTI, A.; REIS, R. P. Fronteira de produção e eficiência econômica na cultura da soja no Mato Grosso do Sul. Revista de Economia e Sociologia Rural, Brasília, v. 41, n. 1, p. 45-61, jan./mar. 2003.

SANTOS, C. et al. Anuário brasileiro da soja 2004. Santa Cruz do Sul: Gazeta, 2004. 152 p.

TOURINO, M. C. C. Arranjo populacional e uniformidade de semeadura na produtividade e outras características agronômicas da soja [Glycine max (L.) Merril]. 2000. 139 p. Tese (Doutorado em Agronomia) - Universidade Federal de Lavras, Lavras, 2000. 


\section{ANEXO}

De acordo com Reis (2002), as terminologias e procedimentos de estimativas de custos de produção adotadas neste trabalho seguem as seguintes operacionalizações:

Depreciação (D): é o custo necessário para substituir os bens de capital quando tornados inúteis, seja pelo desgaste físico ou econômico. O método mais simples de se calcular, e utilizado neste estudo, foi o linear, que pode ser mensurado pela expressão:

$$
D=\frac{V_{a}-V_{r}}{V_{u}}
$$

sendo:

$\mathrm{V}_{\mathrm{a}}$ (valor atual) o valor do recurso, como se fosse adquirido naquele momento (valor de um novo);

$\mathrm{V}_{\mathrm{r}}$ (valor residual) o valor de revenda ou valor final do bem, após ser utilizado de forma racional na atividade;

$\mathrm{V}_{\mathrm{u}}$ (vida útil) o período em anos (meses) pelo qual determinado bem é utilizado na atividade produtiva.

Como sugestão, pode-se ainda utilizar a seguinte expressão para o cálculo da depreciação:

$$
D=\frac{V_{\text {usado }}-V_{r}}{V_{u(\text { restante) }}}
$$

sendo:

$\mathrm{V}_{\text {usado }} \mathrm{o}$ valor do bem em uso pela atividade;

$\mathrm{V}_{\mathrm{u}(\text { restante) }}$ o tempo ainda possível de uso do recurso produtivo.

Custo alternativo (CA): utilizam-se as seguintes expressões para o seu cálculo:

$$
C A=\frac{V_{u}-I}{V_{u}} \cdot V_{a} \cdot \text { taxa de juros (3) ou CA= } V_{\text {usado }} \text { taxa de juros, }
$$

sendo:

I a idade média de uso do bem; se desconhecida, consideram-se $50 \%$ da vida útil $\left(\mathrm{V}_{\mathrm{u}}\right)$. Nesta pesquisa, considerou-se a expressão (3).

Para efeito de análise do custo alternativo, sugere-se considerar a taxa de juros real de $6 \%$ a.a. $(0,5 \%$ a.m.) ou de $12 \%$ a.a. (1\% a.m.), que seria próximo a uma remuneração mínima obtida no mercado financeiro. Neste caso, aplicou-se a taxa de $12 \%$ a. a.

No caso do rendimento alternativo da terra, considera-se o valor de aluguel (arrendamento) da região, sendo que este recurso não é depreciado.

\section{PLANILHAS DE CUSTOS DE PRODUÇÃO}

\section{PLANILHA DO CUSTO FIXOTOTAL DE PRODUÇÃO}

\begin{tabular}{|c|c|c|c|c|c|c|}
\hline Especificação & $\begin{array}{c}\text { Valor atual } \\
(\mathrm{R} \$)^{1}\end{array}$ & $\begin{array}{c}\text { Vida útil } \\
(\text { meses/anos })\end{array}$ & $\begin{array}{c}\text { Depreciação } \\
(\mathrm{R} \$)^{2}(\text { valor } \\
\text { mensal/anual })\end{array}$ & $\begin{array}{c}\text { Custo } \\
\text { alternativo } \\
(\mathrm{R} \$)\end{array}$ & $\begin{array}{c}\text { Custo fixo } \\
\text { parcial } \\
(\mathrm{R} \$)\end{array}$ & $\begin{array}{c}\text { Participação } \\
(\% \text { do CT })^{4}\end{array}$ \\
\hline \multicolumn{6}{|c|}{ CopFT } & CFT \\
\hline
\end{tabular}

Ciênc. agrotec., Lavras, v. 30, n. 6, p. 1146-1153, nov./dez., 2006 
${ }^{1}$ Valor novo;

${ }^{2} \mathrm{D}=\frac{\underline{\mathrm{V}}_{\mathrm{a}}-\mathrm{V}_{\mathrm{r}}}{\mathrm{V}_{\mathrm{u}}} ; \quad \mathrm{D}=\underline{\mathrm{V}}_{\mathrm{usado}}-\mathrm{V}_{\underline{\mathrm{r}}} ;$

${ }^{3} \mathrm{CA}=\underline{\mathrm{V}_{\mathrm{u}}-\mathrm{I}} \cdot \mathrm{V}_{\mathrm{a}} \cdot$ taxa de juros;

$\mathrm{V}_{\mathrm{u}}$

$\mathrm{CA}=\mathrm{V}_{\text {usado }}$ taxa de juros; $\mathrm{I}=$ idade média (se desconhecida, consideram-se $50 \%$ da $\mathrm{V}_{\mathrm{u}}$ );

${ }^{4} \mathrm{CT}=100,00 \%$.

\section{PLANILHA DE CUSTO VARIÁVELTOTAL DE PRODUÇÃO}

\begin{tabular}{|l|l|l|}
\hline \multicolumn{1}{|c|}{ Especificação } & Valor atual (R\$) & \\
\hline & & \\
& & \\
& & \\
& & \\
& & \\
\hline Sub-total $\left(\right.$ CopVT) $^{2}$ & & \\
\hline Custo alternativoção (\% do CT) & \\
\hline CVT & & \\
\hline
\end{tabular}

${ }^{1} \mathrm{CT}=100,00 \%$;

${ }^{2} \mathrm{CA}=$ subtotal /2. taxa de juros, considerando que o capital variável é aplicado parceladamente no período de análise. 